\title{
Accelerated rehabilitation versus conventional rehabilitation in total hip arthroplasty (ARTHA): a randomized double blinded clinical trial
}

\section{Reabilitação acelerada versus reabilitação convencional na artroplastia total do quadril (ARTHA): um ensaio clínico randomizado, duplo cego}

Angela Elizabeth Marchisio ${ }^{1,2}$; Tiango Aguiar Ribeiro ${ }^{1,3,4}$ iD; Carolina Santáanna Umpierres ${ }^{1,2}$; Livia Galvão ${ }^{1,2}$; Ricardo Rosito5; Carlos Alberto de Souza Macedo ${ }^{5,6}$; Carlos Roberto Galia ${ }^{1,5,6}$ (iD.

\section{A B S T R A C T}

\begin{abstract}
Objectives: compare an accelerated physiotherapeutic protocol to a conventional physiotherapeutic protocol in total hip arthroplasty patients. Methods: a randomized double blinded clinical trial performed from August 2013 to November 2014. Forty-eight patients diagnosed with hip osteoarthritis submitted to a total hip arthroplasty surgery. An accelerated rehabilitation physiotherapy applied three times a day and start gait training on the first day or standard physiotherapy applied once a day and start gait training on the second or third day of hospitalization. The Merle dAubigné and Postel score (mobility, pain and gait), muscle strength force, range of motion, in hospital stay and time to start of gait training, were the outcomes. Results: the mean age was 64.46 years (10.37 years standard deviation). No differences were observed in age in different genders, and the two randomization groups were homogeneous. In hospital stay was lower in the intervention group compared to the control group, 3 (3-4) days [median (interquartile range)] versus 4 (4-5) days. Time to the start of gait training was early in the intervention group compared to the control group, 1 (1-1) days versus 2 (2-2) days. Higher muscle strength values were observed in the postoperative results in the intervention group compared to the control group for internal rotation, external rotation and abduction. Conclusions: an accelerated physiotherapeutic protocol should be encouraged, because it shows favourable results in gait, muscle strength and length of hospital stay, even upon hospital discharge.
\end{abstract}

Keywords: Arthroplasty, Replacement, Hip. Musculoskeletal Manipulations. Postoperative Care. Randomized Controlled Trial. Osteoarthritis, Hipl.

\section{INTRODUCTION}

$\mathrm{H}$ p osteoarthritis (OA) affects the locomotor system and leads to pain, disability and functional limitation ${ }^{1-3}$. As the procedure of choice in cases with a lack of response to clinical treatments, total hip arthroplasty (THA) is the most common and the optimal procedure for these patients ${ }^{1,4}$. Despite the excellent results and being considered one of the procedures of the century ${ }^{5}$, THA surgery has a prolonged and often painful rehabilitation ${ }^{6,7}$. These facts can lead to an increased length of hospital stay and increased costs ${ }^{7}$, bringing clinical complications to the patient ${ }^{8-10}$.
Beginning in the mid-1990s ${ }^{11}$ and introduced in orthopedic procedures by Kehlet ${ }^{12}$, the accelerated recovery protocols aim to improve patients' outcomes and accelerate recovery after THA surgery ${ }^{13}$. However, there is no consensus concerning the best protocols to be applied ${ }^{14}$. The vast majority of studies advocate and emphasize the role of multimodal analgesia ${ }^{13,15}$ and do not mention what type of the physiotherapy that should be done. The aim of our study was to conduct a randomized double-blinded trial with the use of the accelerated physiotherapeutic protocol compared to the conventional protocol, and measure its outcomes in a short follow-up period.

1 - Federal University of Rio Grande do Sul (UFRGS), Postgraduate Program in Medicine: Surgical Sciences - Porto Alegre - RS - Brasil 2 - Hospital de Clínicas de Porto Alegre (HCPA), Physiotherapy Group of Hip Surgery of the Department of Orthopedic Surgery - Porto Alegre - RS - Brasil 3 - Universidade Franciscana (UFN), Medicine School - Santa Maria - RS - Brasil 4 - Federal University of Santa Maria (UFSM), Department of Surgery. Medicine School - Santa Maria - RS - Brasil 5 - Hospital de Clínicas de Porto Alegre (HCPA), Hip Surgery of the Department of Orthopedic Surgery - Porto Alegre - RS - Brasil 6 - Federal University of Rio Grande do Sul (UFRGS), Department of Surgery in Orthopaedics. Medicine School - Porto Alegre - RS - Brasil 


\section{MATERIAL AND METHODS}

A randomized double blinded clinical trial was performed from August 2013 to November 2014 in the Hospital de Clínicas de Porto Alegre (HCPA), Federal University of Rio Grande do Sul (UFRGS). The research followed the ethical guidelines of the 1975 Declaration of Helsinki and was approved by the Hospital Ethics Committee and by the Office for Human Research Protections under the number 12-0495. All participants gave informed consent and were informed about the aim of the study. The study followed the CONSORT 2010 guidelines and was registered in Clinical Trials with the number NCT02933632.

The sample size calculation was performed using a pilot study with 14 patients; the minimum sample number was 34 patients (17 in each group). The Sealed Envelope Power (simple size) calculator program was used $^{16}$. The level of significance was $5 \%$, and the power of the sample was $95 \%$.

All patients admitted with hip OA and undergoing THA were eligible. Participants who refused to participate, lived in distant cities, had cognitive disorders that impacted understanding and answering the study questions, were operated under any anesthetic approach other than spinal anesthesia and who did not undergo THA for hip OA were excluded. A total of 50 subjects were initially screened, and 48 patients were included in this study. Two participants declined to participate and were excluded.

All patients had not undergone previous physical therapy. In addition, they had not received any form of preoperative analgesia. All patients participating underwent spinal anesthesia and total hip arthroplasty by the same group of surgeons, who used only the posterior approach for surgical access.

Randomization was performed before the beginning of the study by the Hospital Ethics Committee, and a simple randomization process was carried out, using a sealed bag containing the letters $A$ and $B$. Following the sequence of the randomly selected letters, the allocation of patients was performed when they were admitted to the hospital. Participants who were allocated the letter A received the Standard Assistance Protocol (SAP). Patients who were allocated the letter $B$ received the Accelerated
Rehabilitation Protocol (ARP) for THA. Before enrolment, participants were informed that one group would receive the SAP for THA, while the other group would receive the ARP for THA, although none of the groups was informed about their assigned study group.

The SAP randomization group underwent the following assistance:

- Day 1) Patients started this approach four hours after the operations, after they had been discharged from the anesthesia recovery unit. Patients received verbal orientation and demonstration of the physiotherapy exercises that would strengthen their muscles (gluteus and thighs). They were oriented to the decubitus changes and how to be out of bed. They practiced 3 repetitions of 12 complete movements for each exercise. Some exercises were performed in bed. The patients performed other exercises while sitting in a chair;

- Day 2) Patients repeated the taught exercises of day 1. Following these activities, patients received verbal instructions on gait training, and then, started gait training. Patients started gait training on the day 2 only if they felt safe and claimed that their pain was controlled. Otherwise, training was postponed to the following day;

- Day 3) Patients repeated the events of day 2 , and those patients who had not started gait training on day 2, began it on day 3;

- Day 4 and other days) Patients repeated the gait training until their hospital discharge.

The ARP randomization group received accelerated assistance. The ARP for THA consists of the acceleration of the physiotherapy approach.

- Day 1 - first approach) This was the same as that carried out by the SAP group;

- Day 1 - second approach) Patients repeated the previous exercises - first approach. Following these activities, patients received verbal instructions on gait training, and then, started gait training. Patients started gait training on the second approach only if they felt safe and claimed that their pain was controlled. Otherwise, training was postponed to the following approach;

- Day 1 - third approach) Patients repeated the previous exercises, and those patients who had not started gait training (second approach), began it on the third approach;

- Day 2) Patients repeated day 1 - third approach 
- three times;

- Day 3) Patients repeated the day 1 - third approach - three times.

Throughout the study, none of the groups received a different pain control approach. All patients received Dipyrone $1 \mathrm{~g}$ intravenously every six hours, Tramadol Hydrochloride 100mg intravenously every eight hours and Morphine Sulfate $5 \mathrm{mg}$ subcutaneously every six hours.

The evaluations were performed by a single researcher who was not aware of the interventions. The first evaluation occurred at the time of admission, prior to surgery. The second evaluation (re-evaluation) was carried out at hospital discharge. The measured preoperatively and postoperatively parameters were the same: functional impairment according to goniometry and muscle strength assessment. Mobility, gait, and pain performances were assessed by the Merle d'Aubigné and Postel score ${ }^{17}$. Goniometry was used to evaluate the range of motion in flexion, extension, adduction, abduction, and external and internal rotation of the affected hip ${ }^{18}$. Muscle strength was measured based on Kendall's criteria, and the strength of the muscle groups responsible for flexion, extension, adduction, abduction, external and internal rotation of the affected hip were measured $^{19}$. The muscle strength force scale varies from zero (absence of contraction) to five (normal movement and ability to perform and overcome major resistance). The Merle d'Aubigné and Postel score is composed of a gait, pain and mobility assessments. Each of these items had a maximum score of six (considered best or normal) and a minimum score of one (considered worst or worse change). The hospital discharge criteria for both groups were the absence of pain and an ambulation of more than 150 steps without the aid of others (only using a walker or crutches).

\section{STATISTICAL ANALYSIS}

The statistical analysis was conducted using SPSS version 18.0 (SPSS Inc., IBM Corporation, Armonk, NY). The Kolmogorov-Smirnov test was applied to verify the normal distribution of the variables. Normal quantitative variables are shown as the mean and standard deviation, and non-normal quantitative variables as the median and interquartile range. Qualitative variables are reported as frequencies. An ANOVA test was used to identify age differences between sex and protocol groups. A Levene test was used to assess the homogeneity of the analyzed groups. To verify differences in sex group distributions between the groups, the differences in how the lower limb was operated between the protocol groups and the difference in the incidence of deep venous thrombosis a Pearson chi-square test was used. To identify differences in the in hospital stay and time to start the gait training between groups and sex, a MannWhitney test was performed. To compare preoperative and postoperative results in the same group and the differences in the postoperative results between the two groups, generalized estimating equations (GEE) and the Bonferroni correction test were performed. For the GEE analysis, comparing the postoperative results between the two groups in regard to muscle strength, the Merle d'Aubigné and Postel scores, the importance of length of hospital stay were considered. An interaction between the groups and the length of hospital stay was performed, and then the GEE analysis with Bonferroni correction was carried out. The muscle strength scale was ordinal; therefore, the scores were analyzed according to the Likert scale as a continuous variable. Differences were considered significant when the two-tailed $p$-value was less than 0.05

\section{RESULTS}

Fifty subjects were initially screened, and according to the inclusion and exclusion criteria, 48 subjects were analyzed ( 25 in the SAP group and 23 in the ARP group). The characteristics of the participants are shown in Table I. The mean age of the study population was $64.46 \pm 10.37$ years. There were no age differences between the randomization groups $(p=0.879)$, and they were considered homogeneous ( $p=0.915)$. There were also no age differences between sexes $(p=0.084)$, and the sex groups were homogeneous ( $p=0.310)$. No age differences were observed between sexes in the same randomization group ( $p=0.223$ for the ARP group and $p=0.243$ for the SAP group), and all groups were considered homogenous $(p=0.084$ and $p=0.989$, respectively). No differences were found for sex distribution within groups $(p=0.753)$. 
Table 1. Population characteristics.

\begin{tabular}{lcccc}
\hline & All subjects & $\begin{array}{c}\text { Accelerated rehabilitation } \\
\text { protocol for total hip } \\
\text { arthroplasty (ARP) }\end{array}$ & $\begin{array}{c}\text { Standard assistance } \\
\text { protocol for total hip } \\
\text { arthroplasty (SAP) }\end{array}$ & $p$ - value \\
\cline { 2 - 5 } Age [years] [mean (SD)] & $64.46 \pm 10.37$ & $64.62 \pm 9.79$ & $64.68 \pm 11.07$ & 0.879 \\
$\begin{array}{l}\text { Sex Age [years] [mean (SD), median (IQR)] } \\
\quad \text { Female }\end{array}$ & $67.27 \pm 8.95$ & $67.10 \pm 7.17$ & $67.42 \pm 10.52$ & 0.084 \\
$\quad$ Male & $62.08 \pm 11.05$ & $62 \pm 11.17$ & $62.15 \pm 11.39$ & \\
$\begin{array}{l}\text { Sex (n, \%) } \\
\quad \text { Female }\end{array}$ & $22(45.8)$ & $10(43.5)$ & $12(48)$ & 0.753 \\
$\quad$ Male & $26(54.2)$ & $13(56.5)$ & $13(52)$ & 0.578 \\
$\begin{array}{l}\text { Lower Limb Operated (n, \%) } \\
\text { Left }\end{array}$ & $22(45.8)$ & $11(47.8)$ & $15(60.0)$ & $10(40.0)$ \\
$\quad$ Right & $26(54.2)$ & $12(52.2)$ & &
\end{tabular}

IQR = Interquartile range.

$S D=$ Standard deviation

In-hospital stay was different between the groups ( $p=0.002$ ): 3 (3-4) days [median (interquartile range)] for the ARP group and 4 (4-5) days for the SAP group. No differences were found for in-hospital stay between sexes ( $p=0.084): 4$ (4-5) days for female sex and 4 (3-4) days for male sex.

Three patients presented with complications. Two patients had deep venous thrombosis in the SAP group, while one in the ARP group $(p=0.602)$. There were no complications such as infection, dislocations and neurological injuries.

Considering the time to start the gait training, there was a significant difference between the groups $(p<0,001)$, and no differences were observed between the different sexes $(p=0.098)$. For the ARP group, it was 1 (1-1) days [median (interquartile range)] and for SAP randomization group, it was 2 (2-2) days. For females, it was $2(1-2)$ days, and for males, it was $1(1-2)$ days.

All the groups demonstrated significant improvements when comparing preoperative and postoperative scores for pain considering the Merle d'Aubigné and Postel scores. As for mobility, a small improvement was observed comparing the preoperative and postoperative results in both groups, but this was not statistically significant. The gait assessed by the Merle d'Aubigné and Postel score was significantly worse when comparing the preoperative to postoperative scores, in both groups. No differences were observed comparing only the postoperative scores between the two groups regarding all three items in the Merle d'Aubigné and Postel score. Statistical analysis and values are shown in Table 2.

Table 2. Merle d'Aubigné and Postel scores evaluation.

\begin{tabular}{|c|c|c|c|c|c|c|c|}
\hline & \multicolumn{3}{|c|}{$\begin{array}{l}\text { Accelerated rehabilitation protocol for } \\
\text { total hip arthroplasty (ARP) }\end{array}$} & \multicolumn{3}{|c|}{$\begin{array}{l}\text { Protocolo de assistência padrão para } \\
\text { artroplastia total do quadril (PAP) }\end{array}$} & \multirow[t]{2}{*}{ Intergrupos } \\
\hline & $(n=23)$ & & & $(n=25)$ & & & \\
\hline & $\begin{array}{l}\text { Preoperative } \\
\text { Mean } \pm \text { SE }\end{array}$ & $\begin{array}{l}\text { Postoperative } \\
\text { Mean } \pm \text { SE }\end{array}$ & $\mathrm{p}^{*}$-value & $\begin{array}{l}\text { Preoperative } \\
\text { Mean } \pm \text { SE }\end{array}$ & $\begin{array}{l}\text { Postoperative } \\
\text { Mean } \pm \text { SE }\end{array}$ & $p^{*}$-value & pt-value \\
\hline Pain & $2.13 \pm 0.32$ & $5.61 \pm 0.18$ & $<0.001$ & $2.00 \pm 0.37$ & $5.84 \pm 0.07$ & $<0.001$ & 0.466 \\
\hline Mobility & $3.04 \pm 0.18$ & $3.48 \pm 0.15$ & 0.104 & $3.32 \pm 0.17$ & $3.44 \pm 0.14$ & 0.119 & 0.119 \\
\hline Gait & $3.00 \pm 0.39$ & $1,09 \pm 0.06$ & $<0.001$ & $3.20 \pm 0.37$ & $1.00 \pm 0.00$ & $<0.001$ & 0.600 \\
\hline \multicolumn{8}{|c|}{$\overline{S E}=$ Standard error } \\
\hline $\begin{array}{l}p^{*} \text {-value }= \\
\text { pt-value }=\end{array}$ & $\begin{array}{l}\text { group generalizec } \\
\text { en group generaliz } \\
\text { d hospital stay }\end{array}$ & $\begin{array}{l}\text { estimating equation } \\
\text { ed estimating equati }\end{array}$ & $\begin{array}{l}\text { with Bonfer } \\
\text { ns with Bonf }\end{array}$ & $\begin{array}{l}\text { ni correction comp } \\
\text { roni correction con }\end{array}$ & $\begin{array}{l}\text { rison } \\
\text { parison with an int }\end{array}$ & offect & en protocol \\
\hline
\end{tabular}


Goniometry results are shown in Table 3. No differences were noted by comparing the final postoperative results between the groups (comparison between groups). Within group comparisons, there was a statistically significant difference $(p=0.023)$ with regard to external rotation improvement in the ARP group. Considering the other movements in the ARP group, a better score was observed for the preoperative measurements compared with the postoperative; however, this was not statistically significant. No similar findings were observed for the other movements in the SAP group.
The muscle strength assessment results are shown in Table 4. There were no significant improvements in the muscular groups in the SAP group (within group comparison). On the other hand, a significant improvement was seen for the abduction and external rotation in the ARP group (within group comparison). A comparison of postoperative results between the two groups with an interaction of hospital stay time showed a significant difference with higher scores for subjects who were in the ARP group. Higher scores were found in three important muscle groups: abduction $(p=0.019)$, external rotation $(p=0.002)$ and internal rotation $(p=0.045)$.

Table 3. Results of the goniometric evaluation.

\begin{tabular}{|c|c|c|c|c|c|c|c|}
\hline \multirow[t]{3}{*}{ Movement $\left(^{\circ}\right)$} & $\begin{array}{r}\text { Accelerated } \\
\text { total } h\end{array}$ & $\begin{array}{l}\text { ehabilitation pr } \\
\text { p arthroplasty }\end{array}$ & $\begin{array}{l}\text { tocol for } \\
\text { RP) }\end{array}$ & $\begin{array}{r}\text { Standard assis } \\
\text { ar }\end{array}$ & $\begin{array}{l}\text { ance protocol fo } \\
\text { iroplasty (SAP) }\end{array}$ & otal hip & \multirow[t]{2}{*}{ Inter-groups } \\
\hline & $(n=23)$ & & & $(n=25)$ & & & \\
\hline & $\begin{array}{c}\text { Preoperative } \\
\text { Mean } \pm \text { SE }\end{array}$ & $\begin{array}{c}\text { Postoperative } \\
\text { Mean } \pm \text { SE }\end{array}$ & p-value & $\begin{array}{c}\text { Preoperative } \\
\text { Mean } \pm \text { SE }\end{array}$ & $\begin{array}{c}\text { Postoperative } \\
\text { Mean } \pm \text { SE }\end{array}$ & $p$-value & p-value \\
\hline Flexion & $52.4 \pm 3.1$ & $56.9 \pm 2.6$ & 0.718 & $55.8 \pm 2.9$ & $54.9 \pm 2.3$ & 1.000 & 0.147 \\
\hline Extension & $15.5 \pm 1.4$ & $17.8 \pm 1.3$ & 0.408 & $18.4 \pm 1.6$ & $18.6 \pm 1.6$ & 1.000 & 0.202 \\
\hline Adduction & $17.2 \pm 1.8$ & $18.4 \pm 1.2$ & 1.000 & $19.5 \pm 1.8$ & $18.6 \pm 1.4$ & 1.000 & 0.331 \\
\hline Abduction & $20.4 \pm 1.8$ & $23.7 \pm 1.7$ & 0.409 & $20.9 \pm 1.8$ & $21.8 \pm 1.2$ & 1.000 & 0.331 \\
\hline External Rotation & $12.9 \pm 1.4$ & $17.5 \pm 1.3$ & 0.023 & $13.8 \pm 1.4$ & $15.6 \pm 1.1$ & 1.000 & 0.175 \\
\hline Internal Rotation & $14.2 \pm 1.0$ & $16.3 \pm 1.3$ & 0.765 & $14.9 \pm 1.2$ & $15.1 \pm 1.0$ & 1.000 & 0.239 \\
\hline
\end{tabular}

SE = Standard error.

Table 4. Results of the muscle strength evaluation

\begin{tabular}{|c|c|c|c|c|c|c|c|}
\hline \multirow[t]{3}{*}{ Muscular groups } & \multicolumn{3}{|c|}{$\begin{array}{c}\text { Accelerated rehabilitation protocol for } \\
\text { total hip arthroplasty (ARP) }\end{array}$} & \multicolumn{3}{|c|}{$\begin{array}{c}\text { Standard assistance protocol for total hip } \\
\text { arthroplasty (SAP) }\end{array}$} & \multirow[t]{2}{*}{ Inter-groups } \\
\hline & $(n=23)$ & & & $(n=25)$ & & & \\
\hline & $\begin{array}{c}\text { Preoperative } \\
\text { Mean } \pm \text { SE }\end{array}$ & $\begin{array}{l}\text { Postoperative } \\
\text { Mean } \pm \text { SE }\end{array}$ & $p^{*}$-value & $\begin{array}{c}\text { Preoperative } \\
\text { Mean } \pm \text { SE }\end{array}$ & $\begin{array}{c}\text { Postoperative } \\
\text { Mean } \pm \text { SE }\end{array}$ & $p^{*}$-value & pt-value \\
\hline Flexion & $3.26 \pm 0.22$ & $3.43 \pm 0.12$ & 1.00 & $3.20 \pm 0.15$ & $3.28 \pm 0.14$ & 1.000 & 0.706 \\
\hline Extension & $3.87 \pm 0.20$ & $4.13 \pm 0.13$ & 0.533 & $3.92 \pm 0.14$ & $3.96 \pm 0.12$ & 1.000 & 0.276 \\
\hline Adduction & $3.43 \pm 0.20$ & $3.65 \pm 0.15$ & 1.000 & $3.64 \pm 0.15$ & $3.68 \pm 0.15$ & 1.000 & 0.496 \\
\hline Abduction & $3.17 \pm 0.20$ & $3.74 \pm 0.15$ & 0.006 & $3.48 \pm 0.16$ & $3.48 \pm 0.19$ & 1.000 & 0.019 \\
\hline External Rotation & $2.96 \pm 0.20$ & $3.65 \pm 0.15$ & 0.003 & $3.40 \pm 0.15$ & $3.36 \pm 0.15$ & 1.000 & 0.002 \\
\hline Internal Rotation & $3.30 \pm 0.17$ & $3.70 \pm 0.13$ & 0.188 & $3.52 \pm 0.17$ & $3.44 \pm 0.16$ & 1.000 & 0.045 \\
\hline
\end{tabular}

SE = Standard error.

$p^{*}$-value $=$ Within group generalized estimating equations with Bonferroni correction comparison

pt-value = Between group generalized estimating equations with Bonferroni correction comparison with an interaction effect Between protocol group and hospital stay.

\section{DISCUSSION}

The principles of accelerated recovery protocols are to improve patient outcomes and accelerate recovery following surgery ${ }^{13}$. This approach began in the mid1990s encompassing, colorectal surgical patients ${ }^{11}$. Kehlet $^{12}$ was one of the leading names that brought these principles to hip and knee arthroplasty procedures. 
However, there has been no consensus concerning the physiotherapeutic protocols that can be used. The ARPs take into account the overall concept of patient education, sometimes standardized perioperative anesthesia and local anesthetic infiltration, early mobilization and multimodal analgesia ${ }^{14}$. Some studies $^{13,15}$ emphasize and describe only the preoperative and postoperative protocols of multimodal analgesia, while they forget to emphasize the used physiotherapeutic approach. To our knowledge, our study is one of the few ${ }^{20}$ to address the physiotherapeutic protocol to be used with these patients. After the THA surgery, the patient still presents function disorders, such as a decreased range of motion and muscle strength, postural and ambulation changes, due to motor imbalance. For these reasons, the ARP is justified, because it optimizes the function of these patients and provides an early return to daily living activities $4,21,22$.

According to Jorgensen et al. ${ }^{23}$ and Husted et al. ${ }^{24}$, hospital stay has changed over the years. In Denmark, in the mid-2000s, patients who underwent THA surgery remained in the hospital for about 10 days ${ }^{25}$. However, it is expected that the ARPs lead to a decreased hospital stay ${ }^{4,21,22}$. Some authors report that the estimated hospital stay is about four days with this approach $23,24,26-28$. The Danish Department of Orthopaedic Surgery, considering the real decrease in the hospital stay, began to recommend, from mid-2010, the use of ARPs ${ }^{11,24}$. It is also expected that the number of complications, such as thromboembolic events and risk of hospital infection, would simultaneously decrease with the implementation of the ARPs and the reduction in length of hospital stay ${ }^{8-}$ ${ }^{10}$. Our data have shown that the hospitalization time is shorter in patients who received the ARP compared to those who received the SAP. Although most of these adverse events have not been statistically different, except for the presence of deep venous thrombosis, we did not see any clinical differences regarding the incidence of these complications, similar to what other authors have reported ${ }^{29-32}$. Some articles also report the female sex as a risk factor for increased length of stay ${ }^{28,33-38}$, but this finding was not statistically confirmed by our data.

It was observed that the time to start the gait training was different between the groups. This was one of the initial objectives of the study, to early start gait training in the ARP group, which has been also shown by other authors ${ }^{39,40}$. It was not really known whether this goal would be achieved, since it depended on the patient's perception of safety and on the absence of pain.
Some studies, in order to implement early gait training, performed local capsular tissue and tendon anesthesia during surgery ${ }^{13,41}$. Other authors have reported that patients used pain-blocking medication after the operation such as Pregabalin and Gabapentin, which acts differently to block pain. This approach is known as multimodal analgesia ${ }^{12,42,43}$. However, Smith et al. ${ }^{31}$ showed that the early onset of gait training (i.e., on the same day of surgery) decreased the related pain rates during hospitalization. Following the idea of Smith et al. ${ }^{31}$ who advocate the non-use of a pharmacological approach (neither local anesthesia nor multimodal analgesia), we decided to start the gait training and maintain the same standard of postoperative analgesia which was routinely used in our hospital. This consists of intravenous Dipyrone $1 \mathrm{~g}$ every six hours, Tramadol Hydrochloride $100 \mathrm{mg}$ diluted in $100 \mathrm{~mL}$ of saline solution intravenously every eight hours and Morphine Sulfate $5 \mathrm{mg}$ subcutaneously every six hours. This type o analgesia allowed similar Merle d'Aubigné and Postel's pain scores of, indicating that both groups had a statistically significant improvement. Therefore, in the ARP group, there was an early start of gait training (on the same day of surgery).

Our study demonstrated an improvement in the range of movements in the ARP group, comparing preoperative to postoperative results (although this was not statistically significant). Compared to the study by Peak et al. ${ }^{44}$, our results for motion range were very poor, even in the ARP group. This might be explained because our assessments were carried out on the day of hospital discharge, while Peak et al. ${ }^{44}$ undertook this assessment six weeks after the operation. Therefore, their patients had a longer time to recover their motion range and perform physiotherapy, ultimately demonstrating higher values at the time of re-evaluation, unlike the patients in our study who had a shorter time to improve their range of motion. There is a lack of studies that shows a short-term evaluation of the motion range after ARP. To our knowledge, our study is the only one that has demonstrated this assessment.

An adequate rehabilitation is sought after THA surgery and suitable muscle strength, especially in the abductors, is essential for a good rehabilitation ${ }^{45}$. In other studies, it was observed that muscle strength force decreases in the initial days after THA surgery due to inactivity or pain ${ }^{46,47}$. We found a statistically significant improvement comparing the preoperative and postoperative results in internal rotation, external rotation 
and abduction in the ARP group, and the ARP group was superior to the SAP group. This clearly demonstrates that the purpose of our study and that which is considered essential for THA rehabilitation ${ }^{1,48}$ has been achieved.

\section{STUDY LIMITATIONS}

Our study did not perform multimodal analgesia before and after surgery, but the focus of our study was an accelerated physiotherapeutic and non-analgesic approach. We also did not evaluate the surgical approach (the anterior approach in the case, since the group uses only the posterior approach, as well as incisions shorter than $10 \mathrm{~cm}$ ), since we do not believe that the approach influences the rapid recovery of patients after arthroplasty, which is evidenced by the systematic review of Sharma et al. ${ }^{4}$. Another limitation of our study was that patients' comorbidities, such as hypertension, diabetes, lung diseases, kidney diseases, were not evaluated, and the presence of sarcopenia was not evaluated. These pathologies, as shown by some studies, can interfere with the rehabilitation of the patient, increasing the length of hospital stay ${ }^{49,50}$. However, this is not unanimous in the literature, as other studies have not found this relationship ${ }^{51}$. Therefore, we believe that despite being a limitation of our study, it may not have a great impact since all patients undergo a clinical evaluation prior to surgery, as well as a careful pre-anesthetic evaluation, which means that the patients are clinically stable and have their pathologies adjusted. The small sample size makes it difficult to observe the statistically significant difference in length of stay between the study groups. However, even though it was small, there was a sample calculation to carry out the study, which makes the findings reliable. Nevertheless, our study has several strengths. It is a randomized double blinded study. The number of research subjects was defined by calculating the sample size. The population groups that were randomized were all homogenous, considering age and gender. This allows us to perform comparisons without bias and reach concrete conclusions about the findings of the study. It shows the most used outcome parameters comparable to other articles: in-hospital stay, time to start of gait training and evaluation of pain using an internationally known and validated scale. Additionally, it is one of the few studies reporting the rehabilitation protocol used, and one of the only ones to demonstrate the re-evaluation in a short follow-up time.

\section{CONCLUSION}

Finally, we consider that accelerated rehabilitation, as performed in our randomized doubleblinded clinical trial, leads, in a short follow-up time evaluation (discharge hospital date), to a decreased in length of stay, early onset of gait training, and increased strength of some hip muscles. We believe that the accelerated approach advocated in our study for postoperative total hip prosthesis should be encouraged because of its positive earlier results and patient benefits as well as the easy application of our protocol by physiotherapists.

\title{
R E S U M O
}

\begin{abstract}
Objetivos: comparar um protocolo fisioterapêutico acelerado com um protocolo fisioterapêutico convencional em pacientes submetidos a artroplastia total do quadril. Métodos: ensaio clínico randomizado, duplo-cego, realizado de agosto/2013 a novembro/2014. Quarenta e oito pacientes diagnosticados com coxartrose submetidos a cirurgia de artroplastia total do quadril. Fisioterapia de reabilitação acelerada aplicada três vezes ao dia com início de marcha no primeiro dia ou fisioterapia convencional aplicada uma vez ao dia e início de marcha no segundo ou terceiro dia de hospitalização. Os escores de Merle dAubigné e Postel (mobilidade, dor e marcha), força muscular, amplitude de movimento, internação hospitalar e tempo para o início de marcha foram os desfechos. Resultados: a idade média foi 64,46 anos (desvio padrão 10,37 anos). Não foram observadas diferenças na idade nos diferentes sexos, e os grupos de randomização foram homogêneos. O tempo de internação hospitalar foi menor no grupo intervenção em comparação ao grupo controle, 3 (3-4) dias [mediana (intervalo interquartil)] versus 4 (4-5) dias. 0 tempo para início da marcha foi precoce no grupo de intervenção em comparação ao grupo controle, 1 (1-1) dias versus 2 (2-2) dias. Maiores valores de força muscular foram observados nos resultados pós-operatórios no grupo intervenção em comparação ao grupo controle para rotação interna, rotação externa e abdução. Conclusões: um protocolo fisioterapêutico acelerado deve ser incentivado, pois apresenta resultados favoráveis na marcha, força muscular e tempo de internação, mesmo após a alta hospitalar.
\end{abstract}

Palavras chave: Artroplastia de Quadril. Manipulações Musculoesqueléticas. Cuidados Pós-Operatórios. Ensaio Clínico Controlado Aleatório. Osteoartrite do Quadril. 


\section{REFERENCES}

1. Umpierres $C S$, Ribeiro $T A$, Marchisio $A E$, Galvao $L$, Borges IN, Macedo CA, et al. Rehabilitation following total hip arthroplasty evaluation over short followup time: randomized clinical trial. J Rehabil Res Dev. 2014;51(10):1567-78.

2. Patrizzi LJ, Vilaça KHC, Takata ET, Trigueiro G. Análise pré e pós-operatória da capacidade funcional e qualidade de vida de pacientes portadores de Osteoartrose de quadril submetidos à Artroplastia Total. Rev Bras Reumatol. 2004;44(3):185-91.

3. Sharma L, Kapoor D, Issa S. Epidemiology of osteoarthritis: an update. Curr Opin Rheumatol. 2006;18(2):147-56.

4. Sharma V, Morgan PM, Cheng EY. Factors influencing early rehabilitation after THA: a systematic review. Clin Orthop Relat Res. 2009;467(6):1400-11.

5. Learmonth ID, Young $C$, Rorabeck $C$. The operation of the century: total hip replacement. Lancet. 2007;370(9597):1508-19.

6. Rawal N, Hylander J, Nydahl PA, Olofsson I, Gupta A. Survey of postoperative analgesia following ambulatory surgery. Acta Anaesthesiol Scand. 1997;41(8):1017-22.

7. Dahl JB, Moiniche S. Relief of postoperative pain by local anaesthetic infiltration: efficacy for major abdominal and orthopedic surgery. Pain. 2009;143(1-2):7-11.

8. Cassidy MR, Rosenkranz P, McAneny D. Reducing postoperative venous thromboembolism complications with a standardized risk-stratified prophylaxis protocol and mobilization program. J Am Coll Surg. 2014;218(6):1095-104.

9. Jin F, Chung F. Minimizing perioperative adverse events in the elderly. Br J Anaesth. 2001;87(4):60824.

10. Viliani $T$, Huber $U$, Pasquetti $P$, Poli $P$, Marcucci M, Popolizio A. Rehabilitation after primary total hip replacement. Comparison between Italian and international protocols. Eura Medicophys. 2004;40(2):67-74.

11. Molko S, Combalia A. Rapid recovery programmes for hip and knee arthroplasty. An update. Rev Esp Cir Ortop Traumatol. 2017;61(2):130-8.
12. Kehlet $H$. Fast-track surgery-an update on physiological care principles to enhance recovery. Langenbecks Arch Surg. 2011;396(5):585-90.

13. Tucker A, McCusker D, Gupta N, Bunn J, Murnaghan M. Orthopaedic Enhanced Recovery Programme for Elective Hip and Knee Arthroplasty - Could a Regional Programme be Beneficial? Ulster Med J. 2016;85(2):86-91.

14. Malviya A, Martin K, Harper I, Muller SD, Emmerson $K P$, Partington $P F$, et al. Enhanced recovery program for hip and knee replacement reduces death rate. Acta Orthop. 2011;82(5):577-81.

15. Pitter FT, Jorgensen CC, Lindberg-Larsen $M$, Kehlet $\mathrm{H}$, Lundbeck Foundation Center for Fast-track $\mathrm{H}$, Knee Replacement Collaborative G. Postoperative Morbidity and Discharge Destinations After FastTrack Hip and Knee Arthroplasty in Patients Older Than 85 Years. Anesth Analg. 2016;122(6):180715.

16. Sealed Envelope Ltd. Power calculator for binary outcome superiority trial. 2012 [Available from: https://www.sealedenvelope.com/power/binarysuperiority/.

17. d'Aubigne RM, Postel M. The classic: functional results of hip arthroplasty with acrylic prosthesis. 1954. Clin Orthop Relat Res. 2009;467(1):7-27.

18. Marques AP. Manual de Goniometria. 2a ed. São Paulo: Manole; 2003. 96 p.

19. Miller DW, Hahn JF. General methods of clinical examination. In: Youmans JR, editor. Neurological Surgery. 4th ed: W.B. Saunders Company; 1996. p. 31-2.

20. Wilches C, Sulbaran JD, Fernandez JE, Gisbert JM, Bausili JM, Pelfort $X$. Fast-track recovery technique applied to primary total hip and knee replacement surgery. Analysis of costs and complications. Rev Esp Cir Ortop Traumatol. 2017;61(2):111-6.

21. Tayrose G, Newman D, Slover J, Jaffe F, Hunter T, Bosco J, 3rd. Rapid mobilization decreases lengthof-stay in joint replacement patients. Bull Hosp Jt Dis (2013). 2013;71(3):222-6.

22. Unver B, Karatosun V, Gunal I, Angin S. Comparison of two different rehabilitation programmes for thrust plate prosthesis: a randomized controlled study. Clin Rehabil. 2004;18(1):84-91. 
23. Jorgensen CC, KehletH, Lundbeck Foundation Centre for Fast-track H, Knee Replacement Collaborative G. Fall-related admissions after fast-track total hip and knee arthroplasty - cause of concern or consequence of success? Clin Interv Aging. 2013;8:1569-77.

24. Husted $H$, Jensen CM, Solgaard $S$, Kehlet $H$. Reduced length of stay following hip and knee arthroplasty in Denmark 2000-2009: from research to implementation. Arch Orthop Trauma Surg. 2012;132(1):101-4.

25. Husted H, Holm G, Rud K, Bach-Dal C, Hansen HC, Andersen $\mathrm{KL}$, et al. [Length of stay after primary total hip and knee arthroplasty in Denmark, 20012003]. Ugeskr Laeger. 2006;168(3):276-9. Danish.

26. Jorgensen CC, Kehlet $H$, Lundbeck Foundation Centre for Fast-track $\mathrm{H}$, Knee Replacement Collaborative $\mathrm{G}$. Role of patient characteristics for fast-track hip and knee arthroplasty. Br J Anaesth. 2013;110(6):972-80.

27. Husted H, Hansen HC, Holm G, Bach-Dal C, Rud K, Andersen $\mathrm{KL}$, et al. What determines length of stay after total hip and knee arthroplasty? A nationwide study in Denmark. Arch Orthop Trauma Surg. 2010;130(2):263-8.

28. Husted H, Holm G, Jacobsen S. Predictors of length of stay and patient satisfaction after hip and knee replacement surgery: fast-track experience in 712 patients. Acta Orthop. 2008;79(2):168-73.

29. Khan SK, Malviya A, Muller SD, Carluke I, Partington $\mathrm{PF}$, Emmerson $\mathrm{KP}$, et al. Reduced short-term complications and mortality following Enhanced Recovery primary hip and knee arthroplasty: results from 6,000 consecutive procedures. Acta Orthop. 2014;85(1):26-31.

30. Machin JT, Phillips S, Parker M, Carrannante J, Hearth MW. Patient satisfaction with the use of an enhanced recovery programme for primary arthroplasty. Ann R Coll Surg Engl. 2013;95(8):57781.

31. Smith TO, McCabe C, Lister S, Christie SP, Cross J. Rehabilitation implications during the development of the Norwich Enhanced Recovery Programme (NERP) for patients following total knee and total hip arthroplasty. Orthop Traumatol Surg Res. 2012;98(5):499-505.
32. Larsen K, Hansen TB, Thomsen PB, Christiansen T, Soballe K. Cost-effectiveness of accelerated perioperative care and rehabilitation after total hip and knee arthroplasty. J Bone Joint Surg Am. 2009;91(4):761-72.

33. Rissanen P, Aro S, Paavolainen P. Hospital- and patient-related characteristics determining length of hospital stay for hip and knee replacements. Int J Technol Assess Health Care. 1996;12(2):325-35.

34. Vincent HK, Alfano AP, Lee L, Vincent KR. Sex and age effects on outcomes of total hip arthroplasty after inpatient rehabilitation. Arch Phys Med Rehabil. 2006;87(4):461-7.

35. Le Mar KJ, Whitehead D. Preoperative indicators of length of stay following total hip replacement: a New Zealand-based retrospective, observational study. J Clin Nurs. 2014;23(13-14):2022-30.

36. Mears DC, Mears SC, Chelly JE, Dai F, Vulakovich KL. THA with a minimally invasive technique, multimodal anesthesia, and home rehabilitation: factors associated with early discharge? Clin Orthop Relat Res. 2009;467(6):1412-7. Erratum in: Clin Orthop Relat Res. 2009;467(7):1928

37. Huddleston JI, Wang Y, Uquillas C, Herndon JH, Maloney WJ. Age and obesity are risk factors for adverse events after total hip arthroplasty. Clin Orthop Relat Res. 2012;470(2):490-6.

38. Sibia US, MacDonald JH, King PJ. Predictors of Hospital Length of Stay in an Enhanced Recovery After Surgery Program for Primary Total Hip Arthroplasty. J Arthroplasty. 2016;31(10):2119-23.

39. Okamoto T, Ridley RJ, Edmondston SJ, Visser M, Headford J, Yates PJ. Day-of-Surgery Mobilization Reduces the Length of Stay After Elective Hip Arthroplasty. J Arthroplasty. 2016;31(10):2227-30.

40. Reilly KA, Beard DJ, Barker KL, Dodd CA, Price AJ, Murray DW. Efficacy of an accelerated recovery protocol for Oxford unicompartmental knee arthroplasty--a randomised controlled trial. Knee. 2005; 12(5):351-7.

41. Kerr DR, Kohan L. Local infiltration analgesia: a technique for the control of acute postoperative pain following knee and hip surgery: a case study of 325 patients. Acta Orthop. 2008;79(2):174-83.

42. Joshi GP. Multimodal analgesia techniques and 
postoperative rehabilitation. Anesthesiol Clin North Am. 2005;23(1):185-202.

43. Husted H, Lunn TH, Troelsen A, Gaarn-Larsen L, Kristensen $\mathrm{BB}$, Kehlet $\mathrm{H}$. Why still in hospital after fast-track hip and knee arthroplasty? Acta Orthop. 2011;82(6):679-84.

44. Peak EL, Parvizi J, Ciminiello M, Purtill JJ, Sharkey PF, Hozack WJ, et al. The role of patient restrictions in reducing the prevalence of early dislocation following total hip arthroplasty. A randomized, prospective study. J Bone Joint Surg Am. 2005;87(2):247-53.

45. Johnstone JJ, Noble PC, Hurwitz DE, Andriacchi TP. Biomechanics of the hip. In: Callaghan JJ, Rosenberg A, Rubash HE, editors. The adult hip. 2th ed. Philadelphia: Lippincott, Williams \& Wilkins; 2007. p. 81-90.

46. Appell HJ. Muscularatrophy following immobilisation. A review. Sports Med. 1990;10(1):42-58.

47. Husby VS, Helgerud J, Bjorgen S, Husby OS, Benum $P$, Hoff J. Early maximal strength training is an efficient treatment for patients operated with total hip arthroplasty. Arch Phys Med Rehabil.
2009;90(10):1658-67.

48. Suetta C, Magnusson SP, Rosted A, Aagaard P, Jakobsen AK, Larsen $\mathrm{LH}$, et al. Resistance training in the early postoperative phase reduces hospitalization and leads to muscle hypertrophy in elderly hip surgery patients--a controlled, randomized study. J Am Geriatr Soc. 2004;52(12):2016-22.

49. Elings J, Hoogeboom TJ, van der Sluis $G$, van Meeteren NL. What preoperative patient-related factors predict inpatient recovery of physical functioning and length of stay after total hip arthroplasty? A systematic review. Clin Rehabil. 2015;29(5):477-92.

50. Olthof $M$, Stevens $M$, Bulstra SK, van den AkkerScheek I. The association between comorbidity and length of hospital stay and costs in total hip arthroplasty patients: a systematic review. J Arthroplasty. 2014;29(5):1009-14.

51. Ding ZC, Xu B, Liang ZM, Wang HY, Luo ZY, Zhou $Z K$. Limited influence of comorbidities on length of stay after total hip arthroplasty: experience of Enhanced Recovery after Surgery. Orthop Surg. 2020;12(1):153-61.
Received in: 29/03/2020

Accepted for publication: 08/06/2020

Conflict of interest: no.

Funding source: none.
Mailing address:

Carlos Roberto Galia

E-mail: cgalia@hcpa.edu.br

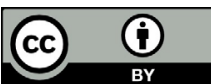

